\title{
MECANISMOS DE PROTECCIÓN DE LOS TENEDORES DE BONOS EN EL MERCADO DE VALORES CHILENO
}

\author{
Jaime Ramiro Gallegos Zúñiga*
}

Fecha de recibido: 28 de febrero de 2013

Fecha de aprobado: 2 de abril de 2013

Artículo de reflexión

Forma de citación: Gallegos, J. R. (2013). Mecanismos de protección de los tenedores de bonos en el mercado de valores chileno. Revista Prolegómenos. Derechos y Valores, $16,31,21-44$

\section{Resumen}

El presente informe busca exponer el régimen general que regula la emisión de bonos en Chile, presentando también algunas breves similitudes y diferencias con algunos aspectos del Derecho comparado.

Una segunda parte de este estudio se centrará en los particulares mecanismos de defensa de los tenedores de bonos, frente a los demás inversionistas, que les posiciona como sujetos privilegiados dentro del ordenamiento jurídico nacional, dada la relevancia que cobra el correcto funcionamiento del mercado de capitales en el país, en atención a la adopción hace más de treinta años de un sistema de capitalización individual de las cotizaciones previsionales.

\section{Palabras clave:}

Bonos, Inversión, Garantías, Mercado de Capitales

\section{DEFENSE MECHANISMS OF BONDHOLDERS IN THE CHILEAN STOCK MARKET}

\begin{abstract}
This report seeks to expose the general rules governing the issuance of bonds in Chile, also presenting briefly some similarities and differences with certain aspects of comparative law.

The second part of this study will focus on the particular defense mechanisms of bondholders, over other investors, positioning them as privileged subjects within the national legal system, given the importance that the proper functioning of the capital market in the country
\end{abstract}

* Abogado de la Universidad de Chile, Magíster en Derecho de los Negocios Internacionales en la Universidad Complutense de Madrid, España. Docente de la Universidad de Chile en pregrado y en otras casas de estudios superiores del país en postgrado. Correo electrónico: jgallegos@derecho.uchile.cl 
has, in consideration to the adoption of a system of social security contributions based on individual capitalization for more than thirty years.

\section{Key words:}

Bonds, Investment, Warranties, Capital Markets

\section{MECANISMOS DE PROTEÇÃO DOS PORTADORES DE TÍTULOS NO MERCADO CHILENO}

\section{Resumo}

O presente relatório procura expor o regim geral que regulamenta a emissão de títulos no Chile, apresentando também algumas breves semelhanças e diferenças com alguns aspectos do Direito comparado.

A segunda parte deste estudo incidirá sobre os particulares mecanismos de defesa dos portadores de títulos, em comparação com outros investidores, posicionando-os como sujeitos privilegiados dentro do sistema jurídico nacional, dada a importância que recebe o bom funcionamento do mercado de capitais no país, em resposta à adoção há mais de trinta anos de um sistema de capitalização individual das contribuições para as pensões.

\section{Palavras-chave:}

Títulos - Investimento - Garantias - Mercado de Capitais

\section{INTRODUCCIÓN}

La globalización ha tendido diferentes redes para permitir el flujo de las inversiones mucho más allá de las fronteras de un Estado, generando permanentes corrientes y desplazamientos de capitales entre los distintos mercados.

En este proceso, las bolsas de Chile, Colombia y Perú emprendieron, ya desde 2011, la tarea de integrarse, mediante el denominado Mercado Integrado Latinoamericano (MILA), lo que ha demandado un permanente proceso de recolección y homologación de información, fijando estándares comunes en los requisitos exigibles a los distintos operadores que acudan a ellas para celebrar transacciones con valores mobiliarios. De ahí la importancia de que se conozcan los diferentes instrumentos de in- versión vigentes en los países que la integran, para así poder hacer efectiva la posibilidad de trasladar capitales a proyectos de diferentes mercados, con la debida información de los distintos mecanismos de protección que brindan los ordenamientos jurídicos para proteger la posición de los inversionistas.

Con este objetivo en mente, creemos oportuno exponer algunos aspectos generales y particulares del proceso de emisión de bonos en Chile, con algunas referencias a la normativa del Derecho comparado, en países tales como Uruguay, Paraguay y Perú, entre otros, con el interés de que el lector pueda conocer las particularidades de estos instrumentos de renta fija en el país y, muy especialmente, los distintos mecanismos especiales de protección que ha estructurado el legislador nacional en esta materia, que permite que el tenedor de bonos 
goce de una posición bastante más ventajosa que la de otros acreedores en el mercado de capitales de este país.

\section{2. ¿QUÉ SON LOS BONOS?}

En España, donde se les denomina obligaciones, Rodrigo Uría ha estructurado una definición muy amplia, al decir: "Todos los títulos que reconozcan o creen una deuda y se emitan en serie impresa y numerada, tendrán la consideración legal de obligaciones, cualquiera que sea la denominación que reciban (cédulas, bonos, etc.)" (1989, p. 465).

En Bolivia, se ha señalado que "la obligación o debenture es "un derecho de crédito, representado por el título en el cual se materializa", es decir, un papel representativo en dinero emitido principalmente por entidades anónimas" (Camargo, 2007, p. 167).

En Chile se le ha definido como "títulos que se emiten en series uniformes y que representan un derecho de crédito en contra de la sociedad emisora, pagadero en determinados plazos y con una tasa de interés dada" (Araya \& Maqueira, 2002, p. 13).

Formulados estos conceptos generales, corresponde exponer la regulación que recibe el proceso de emisión de bonos en Chile, recogiendo también algunas nociones que sobre la materia se presentan en ordenamientos jurídicos de la región.

\section{MARCO NORMATIVO EN CHILE}

Dentro de los distintos mecanismos que nos brinda el mercado de capitales, para que una empresa pueda obtener financiamiento, encontramos la capitalización de utilidades, los créditos bancarios, el leasing, operaciones de descuento, operaciones de factoring, securitización, entre muchas otras (Saieh, 2010, pp. 197-218). Frente a estas, una alternativa algo más compleja, y que usualmente involucra grandes sumas de dinero, es emitir instrumentos de deuda a largo plazo (superior a un año), denominados bonos o debentures, cuya regulación se encuentra contenida en el Título XVI (artículos 103 a 130) de la Ley núm. 18.045, de Mercado de Valores, en la Norma de Carácter General núm. 30 de 1989, que establece las normas sobre inscripción de emisores y valores de oferta pública en el Registro de Valores, y también, en lo que se refiere a su difusión, colocación y obligaciones de información consiguientes, en la sección IV y la Norma de Carácter General núm. 4, de 1982, relativa a las menciones que debe contener la escritura de emisión de bonos.

Además de la regulación específica relativa a los bonos, contenida en los cuerpos normativos indicados, debemos tener presente que, dada la naturaleza de esta operación, ella supondrá una operación de crédito de dinero, por lo que también debemos atender a lo prescrito por las normas sobre esta materia, contenidas en la Ley núm. 18.010, de 1981 sobre operaciones de crédito y otras obligaciones de dinero.

Ahora bien, es útil mencionar que, no obstante este trabajo trate sobre la oferta pública, cabe tener presente que si se efectúa una oferta privada de valores, tal operación queda exenta de la normativa contenida en la Ley núm. 18.045 y de las normas dictadas por la Superintendencia de Valores y Seguros, para la oferta pública de valores, y en aquel supuesto, las partes gozarán de mayor libertad para convenir lo que estimen más adecuado en la satisfacción de sus intereses, primando, por tanto, la autonomía de la voluntad, al no estar, de manera tan evidente, la fe pública involucrada (Puga, 2011, p. 326). Así, en esta clase de operaciones se deben seguir las reglas contenidas en la Norma de Carácter General núm. 336, del 27 de junio de 2012, que establece qué ofertas de valores no son oferta pública, en los términos de la citada Ley núm. 18.045. 
En el Perú, la oferta privada de valores se describe en el artículo 5 de la Ley de Mercado de Valores de 1996, estableciendo, para ello, como criterios de diferenciación los destinatarios de esta y los montos involucrados en la operación.

En ese mismo país, los bonos se configuran del artículo 86 de la Ley de Mercado de Valores, donde se dice que cuando la oferta pública de valores representativos de deuda a un plazo mayor a un año solo puede efectuarse mediante este tipo de instrumentos.

\section{LEY NÚM. 19.301 QUE MODIFICÓ LA LEY NÚM. 18.045 DE MERCADO DE VALORES}

Retomando la oferta pública de valores, y dentro de ella, el proceso de emisión de bonos, es menester indicar que fue la Ley núm. 19.301 de 1994 el cuerpo normativo que buscó establecer un régimen en que se proteja, de manera equitativa, a los distintos tenedores de bonos, confiriéndoles un representante común, quien queda encargado de velar por los intereses del conjunto de estos acreedores, procurando evitar medidas encaminadas al beneficio de unos pocos en detrimento de los demás, como podía darse con la normativa anterior (Ortega, 1997, p. 170) y es por ello que a lo largo de este informe nos detendremos muchas veces en la historia de esta ley, ya que ella nos servirá para descifrar y entender la voluntad del legislador al normar esta materia, y he aquí la causa de esta mención especial.

\section{CONTEXTO DEL MERCADO DE VALORES EN EL PAÍS}

Si bien en el proceso de inversión en valores mobiliarios, van implícitos mayores riesgos que los que traería aparejado el depósito de ahorros en cuentas bancarias, cuyos depositantes o inversores no pretenden "asumir riesgo alguno" (Tapia, 1994, p. 189), por ser el bono un instrumento de renta fija, y por la relevancia que cobra el mercado de valores en Chile, se busca con la regulación, velar por dar la mayor seguridad razonable en el cobro de sus acreencias a los tenedores, ya que en cierta medida, quien invierte en este tipo de instrumentos tiene naturalmente una aversión al riesgo mayor que aquellos sujetos que invierten en instrumentos de renta variable.

Es menester tener presente que en Chile, el mercado de valores cobra gran relevancia, habida consideración, entre otros aspectos, cómo desde 1980 participa en él un grupo de actores de enorme peso económico y trascendencia social, que aparecieron a partir de la modificación del sistema de pensiones de vejez, invalidez y sobrevivencia, lo cual supuso la configuración de sociedades anónimas especiales, denominadas administradoras de fondos de pensiones, las que tienen como objeto obtener la más alta rentabilidad del proceso de inversión las cotizaciones previsionales de los trabajadores, entre los distintos instrumentos financieros del mercado, conforme a las reglas propias de cada uno de los 5 fondos que manejan, para luego, entregar la pensión respectiva en función del monto que se haya acumulado en las cuentas de capitalización individual de cada uno de los cotizantes, la cual se compondrá de las sumas mismas aportadas mes a mes más los resultados y utilidades de aquellas.

Precisamente, las entidades que generalmente adquieren estos instrumentos de renta fija, los bonos, son las administradoras de fondos de pensiones, como inversionistas institucionales (Novoa \& Novoa, 1997, p. 122), puesto que manejan elevadas sumas de dinero $y$, como entidades especializadas en asuntos de inversión, cuentan con bastante información respecto a los emisores, los instrumentos transados y las fluctuaciones del mercado. Dado este contexto en particular, resulta necesario asegurar la recuperación de la inversión efectuada por medio de diferentes mecanismos especiales concebidos para este fin. 
A tal efecto, el artículo 45, letras e) y f), del DL 3500 señala que las Administradoras de Fondos de Pensiones cuentan como alternativa de inversión los bonos, ya sea que estos sean emitidos por empresas públicas o privadas y también los bonos convertibles en acciones.

Ahora bien, no cualquier bono puede ser objeto de adquisición por parte de las Administradoras de Fondos de Pensiones, ya que se ha establecido como requisito el que tales instrumentos de deuda cuenten con, al menos, dos clasificaciones de riesgo igual o superior a BBB y Nivel N-3, elaboradas por diferentes clasificadoras privadas.

La clasificación "BBB", si bien no es la más alta, corresponde, conforme a lo dispuesto por el Art. 88 de la Ley núm. 18.045, a aquellos instrumentos que cuentan con capacidad para el pago del capital e intereses en los términos y plazos pactados, pero esta es susceptible de debilitarse ante posibles cambios en el emisor, en la industria a que pertenece o en la economía.

El Nivel N-3 por su parte hace referencia a aquellos instrumentos que cuentan con suficiente capacidad de pago del capital e intereses en los términos y plazos pactados, pero esta es susceptible de debilitarse ante posibles cambios en el emisor, en la industria a que pertenece o en la economía.

Formulado este contexto general, creemos oportuno exponer algunas de las ideas básicas de los legisladores al normar esta materia, para lo cual, estimamos adecuado exponer las declaraciones del entonces Diputado Claudio Huepe, al momento de discutir la tramitación de la citada Ley núm.19.301, en relación a la relevancia del mercado de capitales en el país, quien señaló: "En Chile, el desarrollo del mercado de capitales es más importante que en otros países de similar grado de desarrollo, fundamentalmente, por dos razones: por el rol preponderante que juegan los inversionistas institucionales como demandantes de títulos destinados a la inversión, y por la mayor participación que le corresponde al sector privado como motor de la inversión, incluso en sectores de infraestructura y servicios públicos que requieren de acceso a fuentes de recursos a más largo plazo" (Historia de la Ley núm. 19.301, p. 290).

Por su parte, el entonces Diputado Jaime Orpis, también integrante de la Comisión de Hacienda de la Cámara Baja, se refirió en elogiosos términos a la regulación proyectada, en especial en lo referente a los bonos, al decir (Historia de la Ley núm. 19.301):

El proyecto en análisis propone la creación de nuevos instrumentos de ahorro financiero. Me parece de particular relevancia la creación legal de los bonos para proyectos sin historia, pues constituyen un mecanismo de financiamiento moderno $y$ eficiente. Se trata de un mecanismo de amplia difusión a nivel internacional. Se adopta el calificativo de bonos, restringiéndolo a aquellos papeles de deuda a plazos mayores de un año con ciertas características básicas que la ley norma. Al mismo tiempo, se regula el papel de los tenedores de bonos, la necesidad de que tengan un representante que vigile sus intereses, las estipulaciones para que dicho representante pueda actuar frente a las empresas que emiten los bonos y las atribuciones y las penalidades para conductas inadecuadas en este ámbito (p. 326).

De estos postulados podemos sostener que lo que buscó la referida Ley núm.19.301 fue perfeccionar los instrumentos transables en el mercado de capitales chileno, permitiendo así la diversificación de las inversiones que efectúen las Administradoras de Fondos de Pensiones $y$, con ello, permitir a su vez, que las empresas locales cuenten, si cumplen con los requisitos establecidos, con nuevos mecanismos de financiamiento para emprender sus proyectos, y así alcanzar un flujo rentable de los recursos.

Por todas estas consideraciones, resulta interesante detenerse a analizar los distintos medios 
establecidos en defensa de los inversionistas de estos instrumentos, habida cuenta, además, del efecto reflejo que ha tenido el sistema de capitalización individual de los fondos de pensiones chileno, en distintos países de la región y también en otros tantos de Europa del Este.

\section{AGENTES QUE PARTICIPAN EN EL PROCESO DE EMISIÓN DE BONOS}

\subsection{Emisor (sujeto habilitado)}

Será aquella sociedad que ha decidido obtener financiamiento acudiendo a este mecanismo de deuda a largo plazo.

Podrán emitir bonos sociedades de diferente naturaleza societaria.

A este respecto, podemos señalar que la legislación anterior a la Ley núm.18.045, la Ley vigente de Mercado de Valores en Chile, contenida en aquel entonces en el DL 1.064 de 1975, expresamente se indicaba que "sólo podrán contratar empréstitos mediante la emisión de bonos o debentures (...) las sociedades anónimas constituidas en Chile", restricción que no se contiene en la normativa actualmente en vigor.

No obstante, la normativa contenida en la Ley núm. 18.045 no restringe la posibilidad de que las entidades que emitan bonos sean solamente las sociedades anónimas, dados los numerosos requisitos establecidos para desarrollar válidamente este proceso, a través de una oferta pública de valores, es natural y mayoritario, desde un punto de vista estadístico (Puga, 2011 , p. 323), que sea tal tipo societario, en particular las sociedades anónimas abiertas, las que empleen con mayor frecuencia este mecanismo de financiamiento.

Revisando la situación en la región, podemos mencionar que en el Uruguay las entidades habilitadas para emitir bonos no se encuentran restringidas a un tipo societario particular puesto que, conforme a lo establecido en el artículo 63 de la Ley de Mercado de Valores de ese país, pueden emitir obligaciones negociables (equivalentes a nuestros bonos) las sociedades comerciales nacionales o extranjeras, las cooperativas, los entes autónomos y servicios descentralizados del dominio industrial y comercial del Estado y las personas públicas no estatales con actividad industrial y comercial.

En el Perú, el artículo 86 de su Ley de Mercado de Valores de 1996, admite también que otras personas jurídicas de Derecho Privado, diferentes a las sociedades anónimas, puedan de emitir bonos.

En cambio, en Guatemala se limita la posibilidad de que otras sociedades puedan emitir bonos, ya que el artículo 544 de su Código de Comercio se definen las obligaciones (equivalentes a nuestros bonos) como: "títulos de crédito que incorporan una parte alícuota de un crédito colectivo constituido a cargo de una sociedad anónima".

\subsubsection{Emisor (decisión de emitir bonos)}

En lo que atañe a la verificación de la voluntad para emitir este título de deuda, en el caso de las sociedades anónimas, dada la relevancia y las altas sumas involucradas en un proceso de este tipo, tal decisión debe ser acordada en una junta extraordinaria de accionistas, citada para tal efecto, conforme a lo establecido en el Art. 57 № 3 de la Ley № 18.046, sobre Sociedades Anónimas. Decisión, que en todo caso, no requiere de un quórum especial para su perfeccionamiento, salvo que para garantizar el pago de la suma respectiva, la sociedad se obligue a prestaciones de dar, hacer o no hacer más exigentes, como se tendrá oportunidad de abordar más adelante.

Acordada la colocación de este instrumento de deuda, la sociedad emisora asumirá una serie de obligaciones que se detallarán en el con- 
trato respectivo, operando en su defecto las normas mínimas establecidas por el legislador para tal efecto.

La obligación fundamental del emisor con sus acreedores es la contenida en el artículo 120 de la citada Ley núm. 18.045 que señala que: "El emisor deberá pagar fiel e íntegramente a los tenedores de bonos todas las sumas que les adeude por concepto de amortizaciones de capital, reajustes y condiciones establecidas en el contrato de emisión".

En el proyecto original presentado por el Ejecutivo, que posteriormente se traduciría en la Ley núm. 19.301, también figuraba, de manera expresa, que el emisor debía pagar fielmente las garantías, expresión que fue correctamente eliminada en el Senado, ya que las garantías no siempre deberán ser pagadas, puesto que estas deben ser solventadas solo si no se verifica el cumplimiento en tiempo y forma de la obligación principal por parte del emisor, dado su carácter accesorio (Historia de la Ley núm. 19.301, 541).

\subsection{Tenedores de Bonos}

Son los acreedores de la sociedad emisora, quienes adquieren para sí este título de deuda a largo plazo.

Como ya hemos dicho, resulta fundamental que los tenedores de bonos cuenten con información suficiente para efecto de poder adoptar las decisiones de inversión, conforme al riesgo específico que se quiera asumir. Tal suministro de información ha sido catalogado como una verdadera exigencia de lex artis del mercado de valores (Zunzunegui, 2006, p. 198).

Ahora bien, se ha estimado que entre más "sofisticado" (Malumián \& Barredo, 2007, pp. 40-41) sea el receptor de la oferta pública de valores, menos deben ser los requisitos establecidos por el legislador en su resguardo, ya que se supone que tales actores cuentan con mayor y mejor información respecto a las operaciones del mercado de valores y también de las eventuales fluctuaciones que pudieren afectarles. De ahí que resulte fundamental el encontrar un justo punto medio que cautele el interés de los inversores, pero que no trabe indebidamente el proceso mismo de emisión con procedimientos engorrosos y costosos que hagan que este método de financiamiento sea poco eficaz.

\subsubsection{Mecanismos de actuación de los tenedores de bonos}

Estos inversionistas se reúnen en juntas de tenedores de bonos, ya sean ordinarias o extraordinarias, con el objeto de abordar materias de interés común, como por ejemplo, el acordar -eventualmente- una modificación de los términos del contrato de emisión respectivo con la sociedad emisora.

Sobre este punto, creemos adecuado destacar el hecho de que el legislador buscó que los tenedores de bonos adopten las decisiones respecto de sus acreencias en asamblea, procurando respetar y velar por el interés común de todos ellos (Historia de la Ley núm. 19.301, p. 295), para así evitar que las negociaciones o el actuar particular de uno o un grupo de ellos perjudique al resto de los inversores, habida cuenta de que en esta materia también va implícita la fe pública del mercado de capitales, que se puede ver mermada si los inversionistas de mayor envergadura buscan satisfacer únicamente sus intereses particulares, en detrimento de los inversionistas minoritarios.

No obstante lo anterior, se mantiene también la posibilidad de actuar individualmente en aspectos relacionados con el pago oportuno del capital e intereses de cada uno de los tenedores de bonos (artículo 107, inciso final y artículo 120 de la referida Ley núm. 18.045)

Por otra parte, el Art. 125 de la aludida Ley núm. 18.045 es el encargado de establecer el quórum necesario para adoptar los acuerdos en que se modifiquen los términos del contrato de emisión; este artículo indica que en junta 
extraordinaria de tenedores de bonos se podrá acordar, con el voto de las dos terceras partes de los tenedores de la emisión respectiva, la modificación del contrato de emisión, salvo que el contrato mismo haya establecido otro quórum más alto.

Ahora bien, cuando lo que se quiera modificar sea la tasa de interés o de reajustes, oportunidades de pago, monto y vencimiento de las amortizaciones de la deuda o de las garantías contempladas en la emisión original, se exige que el quórum establecido en la escritura que materializa este contrato no sea inferior al $75 \%$ de los tenedores de la emisión respectiva. En caso de que no se establezca un quórum para estas modificaciones en la escritura correspondiente, tales cambios deberán contar con el voto conforme de la totalidad de los tenedores.

El que sólo se necesite el 75\% obedeció a una flexibilización introducida con la Ley núm. 20.190, de 2007 que modernizó la regulación del mercado de capitales, pues antes del cambio indicado para adoptar válidamente este tipo de modificaciones se requería, siempre, del voto conforme de la unanimidad de los tenedores de la emisión correspondiente.

Será el representante de los tenedores de bonos el encargado de ejecutar los acuerdos que se adopten en aquellas juntas.

En el Uruguay, la Ley de Mercado de Valores, en su artículo 66 literal k también establece como quórum mínimo para dar lugar a la modificación del contrato de emisión de obligaciones negociables (bonos), sin distinguir la materia de que se trate, el $75 \%$ del monto del total circulante de la emisión.

En la legislación peruana, en cambio, la Ley del Mercado de Valores de ese país, en su artículo 94, entrega a la decisión de la asamblea de obligacionistas la facultad para decidir la modificación del contrato de emisión, sin establecer quórum mínimo para tal efecto.

\subsection{Representante de los tenedores de bonos: entidades habilitadas para desempeñar la función}

En Chile pueden ejercer tales funciones los bancos, sociedades financieras y demás personas que, para tal efecto, autorice la Superintendencia de Valores y Seguros, mediante norma de carácter general, siempre y cuando acrediten y mantengan un patrimonio mínimo de 5000 Unidades de Fomento (unidad reajustable de acuerdo a la variación de la inflación, cuya suma a la fecha, corresponde en 1 UF a alrededor de US\$50), conforme a los términos del artículo 104 y 115 de la Ley núm.18.045.

El artículo 73 de la Ley de Mercado de Valores del Uruguay establece una disposición análoga al prescribir que, cuando se trate de una colocación mediante oferta pública, el emisor deberá celebrar con una institución de intermediación financiera, con intermediarios de valores $\mathrm{u}$ otras entidades especializadas, autorizadas para tal efecto por la Superintendencia de Servicios Financieros, un convenio por el que estas tomen a su cargo la representación de los titulares de valores durante la vigencia de la emisión hasta su cancelación total.

También contiene una normativa similar la legislación paraguaya, en cuyo artículo 52 de la Ley de Mercado de Valores núm. 1284 de 1998 , se señala que solo los bancos y demás entidades financieras, los intermediarios de valores, las empresas fiduciarias $u$ otras entidades especializadas autorizadas al efecto por la Comisión (de Mercado de Valores) podrán desempeñar tal función.

En cambio, la Ley del Mercado de Valores de Perú, de 1996, entrega la regulación de esta materia a una Norma de Carácter General dictada por la Superintendencia del Mercado de Valores, señalando en términos amplios que puede ser representante de los obligacionistas toda persona natural o jurídica que cumpla con los requisitos establecidos por la Superintendencia. 
Creemos oportuno mencionar que la normativa chilena vigente, que limita la posibilidad a que otras entidades puedan actuar como representantes de los tenedores de bonos, supone un cambio respecto de la anterior regulación de este tipo de materias, contenida en aquel entonces en el Decreto Ley núm. 1.064, de 1975, en cuyo Art. 42, se disponía que pueden ser representantes de tenedores de bonos las personas naturales que no tengan incapacidad legal para desempeñar mandatos y las instituciones financieras expresamente facultades para ello, confiriendo un margen bastante más amplio de eventuales sujetos que pudieren ejercer tal función.

Ni el representante de los tenedores de bonos, ni el administrador extraordinario (que se verá más adelante) pueden ser personas relacionadas con el emisor, en mérito a lo establecido en el artículo 116 inciso segundo de la citada Ley núm. 18.045. Con esta norma lo que se busca es mermar el conflicto de intereses que pudiere producirse entre el representante de los tenedores de bonos y el emisor, quien por lo demás lo elige y lo remunera, lo que se da en mérito a la paradoja de que tal representante debe cumplir una serie de funciones de unos representados (los tenedores) que aún no existen (Rodríguez, 2004, p. 449).

Cabe mencionar, que la figura de un representante común de los tenedores de bonos se repite en el Derecho Comparado y, en particular, en la región lo podemos apreciar en lo contenido en el Art. 554 núm. 5 del Código de Comercio de Guatemala, también en el artículo 51 de la Ley núm. 1284/98, Ley de Mercado de Valores del Paraguay, y en el artículo 69 de la Ley del Mercado de Valores de México, del año 2005, a título meramente ejemplar.

En el caso del Perú, si bien la Ley del Mercado de Valores de ese país contempla la figura del representante de los "obligacionistas", en el Art. 87 de tal cuerpo normativo exime de tal requisito cuando la oferta es dirigida a inversionistas institucionales, pues se entiende que estos no requieren de una protección especial.

En aquel país puede ser designado representante de los "obligacionistas" cualquier persona natural o jurídica que cumpla con los requisitos establecidos por la Superintendencia del Mercado de Valores mediante norma de carácter general. En cualquier caso, no puede designarse como representante de los "obligacionistas" al emisor, a la entidad estructuradora ni a las personas con las que estos tengan vinculación, conforme a las normas que apruebe la Superintendencia, de acuerdo a lo ordenado por el inciso segundo del artículo 87 de la referida Ley del Mercado de Valores de ese país.

\subsubsection{Representante de los tenedores de bonos (ejercicio de la función)}

Respecto al rol que les cabe a los bancos en esta operativa, debemos mencionar que este puede materializarse a través de diferentes vías, ya sea colaborando en la preparación de la oferta de valores, tendiendo caminos para la adquisición de estos instrumentos por parte de los inversionistas o facilitando su distribución entre el público, como también facilitando la inversión de sus clientes en tales valores. Otra posibilidad, de especiales características, es que actúe como entidad fiduciaria, en carácter de representante de los tenedores de bonos, en cuyo caso, lo que se le encarga es actuar en función de los intereses de estos inversionistas (García-Pita, 2009, pp. 608-723).

Este representante, que actúa como mandatario de los tenedores (Torres, 2010, p. 322), responde de su encargo por culpa leve. En el Perú, en términos análogos se señala en el artículo 92 que el representante de los "obligacionistas" debe actuar en el ejercicio de sus funciones con la diligencia de un ordenado comerciante, cuidando de los intereses de los obligacionistas como de los propios. 
Al revisar la historia de la Ley núm. 19.301 de 1994, que como ya hemos dicho estructuró a estos representantes, en el Mensaje del Ejecutivo se hace expresa mención a la necesidad de contar con un sujeto que vele por el interés común de los distintos acreedores, ya que antes de aquella modificación se constató que, en muchos casos, aquellos tenedores con mayor poder de negociación se encontraban en mejor situación que aquellos tenedores minoritarios que muchas veces se veían perjudicados por las negociaciones particularmente convenidas (Historia de la Ley núm. 19.301, 4).

Es una tarea propia del representante, como ya hemos mencionado, el velar por el interés común de los tenedores, tanto judicial como extrajudicialmente. En tal cometido, puede solicitar la información plena y documentada que sea necesaria, tanto al emisor como a los auditores externos de este, pudiendo requerir toda aquella relativa a la marcha de la empresa, debiendo, en todo caso, guardar la debida reserva de la información de la cual toma conocimiento en ejercicio de esta función, lo que resulta coherente con el "deber de confidencialidad" tan propio de la actividad bancaria en general (Boneo \& Barreira, 1994, p. 49), criterio que también se reproduce en la legislación peruana, cuyo Art. 93 de la Ley del Mercado de Valores de ese país consagra ese deber de reserva.

El propio artículo 108 de la Ley núm.18.045, de Chile, señala que el representante, en la obtención de aquella información, no puede afectar la gestión social, lo que es de toda lógica, si entendemos que uno de los principios rectores que rigen las transacciones $y$, en particular, las acreencias que mantienen los inversores de un proyecto, es que se deben llevar a cabo todas las medidas necesarias para conseguir el "éxito de la financiación", lo que generará beneficios, tanto para el requirente, como también para el oferente de capital (López, 2001, p. 299)

Otro punto que nos parece digno de rescatar es que en el proyecto presentado por el Eje- cutivo, que posteriormente se traduciría en la Ley núm. 19.301, se contemplaba la facultad del representante de los tenedores de bonos de "examinar los libros del emisor cuando lo estime necesario para proteger los intereses de sus representados", facultad que a proposición de la Senadora, doña Olga Feliú Segovia fue eliminada, por entender que tal facultad excede todas las reglas generales en materia comercial, donde, por regla general, solo se admite la revisión parcial y no total de los libros de contabilidad, a menos que una diligencia completa, de este tipo, sea autorizada por un juez, en casos calificados (Historia de la Ley núm. 19.301, pp. 534- 535).

Tal supresión nos lleva a concluir que el representante de los tenedores de bonos no se encuentra habilitado para revisar por sí los libros del emisor, y sus atribuciones se limitan a solicitar información documental para el fiel cumplimiento de su cometido.

Precisando en algo el alcance de este deber-facultad, el artículo 110 de la Ley núm. 18.045 acota el margen de la información que debe serle suministrada al representante de los tenedores de bonos, puesto que allí se indica que el emisor debe entregarle a este la información pública que entrega a la Superintendencia que le fiscaliza, en el mismo momento que a ésta.

A modo de síntesis, las facultades y deberes generales de los representantes de los tenedores de bonos, además de lo ya indicado, conforme a lo establecido en el artículo 109 de la mencionada Ley núm. 18.045 son:

a) Verificar el cumplimiento, por parte del emisor, de los términos, cláusulas y obligaciones del contrato de emisión, conforme a la información que éste le proporcione;

b) Informar de lo anterior a los tenedores, en la forma y periodicidad que la Superintendencia determine mediante una norma de carácter general;

c) Verificar, periódicamente, el uso de los fondos declarados por el emisor en la for- 
ma y conforme a los usos establecidos en el contrato de emisión;

d) Velar por el pago equitativo y oportuno a todos los tenedores de bonos, de los correspondientes intereses, amortizaciones y reajuste de los bonos sorteados o vencidos.

El representante deberá siempre efectuar los pagos por intermedio de un banco o institución financiera, a menos que tuviera alguna de dichas calidades, eventualidad en que podrá pagar directamente.

e) Acordar con el emisor las reformas específicas al contrato de emisión que le hubiere autorizado la junta de tenedores de bonos, en materias de la competencia de esta, $y$

f) Ejercer las demás funciones y atribuciones que establezca el contrato de emisión.

Además, se permite que el representante pueda asistir, sin derecho a voto, a las juntas de accionistas del emisor, según lo prescribe el artículo 108 de la aludida Ley núm. 18.045.

A todo lo anterior, se une el hecho de que, convencionalmente, para hacer el título de deuda más atractivo a los futuros tenedores de bonos, se permite que se confiera al representante de los tenedores de bonos ciertas facultades en materia de administración de la sociedad emisora, pudiendo pactarse que se requiera su autorización para la adopción de ciertos acuerdos o para llevar adelante determinadas operaciones, con lo cual se procura velar de la mejor manera por el correcto andar de la compañía, que luego le permitirá dar cumplimiento a los compromisos asumidos en virtud de la emisión de este título.

En el fondo se permite la posibilidad de delegar determinadas facultades, con acuerdo de la mayoría de las acciones con derecho a voto, al representante de los tenedores de bonos.

Con todo, el legislador impide, en las sociedades anónimas abiertas, que tal delegación suponga el infringir las normas relativas a reparto mínimo de dividendos, dado lo esta- blecido en el artículo 111 inciso tercero de la Ley núm.18.045, que debe relacionarse con lo señalado por el artículo 79 de la Ley núm. 18.046, Ley de Sociedades Anónimas que regula estas materias.

En lo relativo a la defensa judicial de los intereses de los tenedores de bonos, podemos mencionar que para desarrollar esta, el representante de los tenedores de bonos se encuentra legalmente investido de todas las facultades ordinarias establecidas en el artículo $7 \mathrm{del}$ Código de Procedimiento Civil (que regula el mandato judicial), y de aquellas especiales que le otorguen la junta de tenedores de bonos, conforme a lo establecido por el Art. 107 de la mencionada Ley núm. 18.045.

Ahora bien, el artículo 120 de la Ley núm. 18.045 señala que las acciones procesales conducentes a obtener la exigibilidad y cobro anticipado de uno o más bonos de una emisión, sea por mora en el pago de cualquiera de ellos, por infracción de las demás obligaciones consignadas en los resguardos establecidos en la escritura de emisión o por cualquiera otra causa, sólo podrán decidirse por la junta de tenedores de bonos con el quórum de mayoría absoluta de los bonos asistentes de la respectiva emisión.

Ese mismo acuerdo previo se requiere para la interposición de demandas destinadas a que se declare judicialmente la resolución del contrato de emisión con indemnización de perjuicios; la petición de declaración de quiebra del emisor, la presentación de proposiciones de convenios extrajudiciales o judiciales preventivos de este deudor con sus acreedores y su participación en ellos, cualquiera sea quien los proponga, y, en general, cualquiera otra petición o actuación judicial que comprometa el interés colectivo de los tenedores de bonos de una emisión.

En tales casos, las demandas respectivas deberán interponerse por el representante de los tenedores de bonos y el título ejecutivo, en su caso, deberá ser complementado por una co- 
pia del acta de la junta respectiva, reducida a escritura pública por dicho representante.

Respecto a esta materia, el artículo 55 de la Ley núm. 1284 de 1998 del Mercado de Valores de Paraguay, señala que el representante de los obligacionistas tendrá a su cargo la defensa de los derechos e intereses que colectivamente correspondan a los obligacionistas, para lo cual detentará los poderes de un mandatario general.

Cabe tener presente, conforme a lo establecido en el inciso segundo del artíulo 115 de la Ley núm. 18.045, que las funciones de los tenedores de bonos y de los administradores extraordinarios son indelegables, sin que valga ninguna estipulación en contrario para suprimirlas, limitarlas o modificarlas.

Una particularidad bastante interesante es que la remuneración de este representante es a cargo del emisor y goza de preferencia de primera clase en su cobro, de aquella que norma el artículo 2472 núm. 1 del Código Civil.

\subsubsection{Remoción del representante de los tenedores de bonos}

Cuando en el Congreso Nacional se discutió la incorporación de los representantes de los tenedores de bonos se les concibió como "fiscalizadores permanentes de la conducta y cumplimiento del emisor de esos títulos" (Historia de la Ley núm.19.301: 295), con la particularidad de que este sujeto es elegido por el propio emisor, esto es por la contraparte de los intereses que representa. Mas, por tal motivo, aquel representante así designado puede ser libremente removido por los tenedores de bonos, sin expresión de causa, conforme a lo señalado por los artículos 104 y 109 de la citada Ley núm. 18.045.

Será esa misma junta de tenedores de bonos la encargada, en caso de remover al representante elegido por el emisor, de designar a un nuevo representante, para cuyo efecto no será necesario modificar la escritura de emisión de bonos, pero sí notificar de tal cambio al emisor y a la Superintendencia de Valores y Seguros, al día hábil siguiente a que se haya practicado tal reemplazo.

Sobre esta temática, el inciso tercero del artículo 73 de la Ley Uruguaya de Mercado de Valores establece un quórum mínimo del $75 \%$ del total de la emisión para la remoción del representante de los titulares de estos valores y para la modificación de las condiciones de la emisión, de las fechas de pago, otorgamiento de quitas o esperas, modificaciones en las fechas de pago o intereses, modificación de las monedas de pago y otras que el contrato establezca. Tales acuerdos, en el caso de que cumplan los quórum allí señalados son oponibles a la totalidad de los tenedores.

\subsection{Administrador extraordinario}

Será necesario que se nombre un administrador extraordinario en el evento del Art. 112 de la Ley núm. 18.045, esto es, cuando la finalidad de la colocación de los bonos fuere la de financiar nuevos proyectos de inversión del emisor, por un monto superior al $40 \%$ del valor total de su activo individual existente antes de la emisión, que exijan la aplicación en etapas sucesivas de los recursos captados, durante un período superior a un año.

Ahora bien, el caso aludido apunta a los supuestos en que el legislador exige el nombramiento de un administrador extraordinario. Sin embargo, nada obsta a que, si el emisor quisiere hacer más atractivo el bono que pretende colocar, ofrezca mayores garantías para los futuros tenedores, y de motu proprio, aun cuando no emita un monto igual o superior al $40 \%$ de su activo, establezca un administrador extraordinario, el que se encontrará con los poderes y facultades establecidos en el contrato de emisión respectivo, y en subsidio por las normas dadas por la Ley. 
El rol del administrador es supervigilar la ejecución del propósito para el cual se captaron los recursos con el proceso de emisión de los bonos, liberando, en caso positivo, las sumas respectivas, según el cumplimiento de las distintas etapas del proyecto.

De hecho, el legislador establece que es el administrador quien por cuenta del emisor recibe el dinero obtenido en la colocación de los bonos y, luego, lo pondrá oportuna y periódicamente a disposición de la administración de la sociedad emisora, en la medida en que se cumplan con los requisitos de avance de la obra y otros requisitos establecidos en el contrato de emisión.

Por otra parte, se faculta al administrador extraordinario a suspender los desembolsos que corresponda efectuar al emisor, cuando este último no hubiere cumplido fiel y oportunamente las condiciones u obligaciones establecidas en la escritura de emisión, conforme a lo establecido en el artículo 112 inciso sexto de la citada Ley núm. 18.045.

Aquel administrador extraordinario debe invertir los fondos que reciba siguiendo las instrucciones del emisor, conforme a la política de inversiones establecida en el contrato de emisión, una vez que éste haya dado cumplimiento a sus obligaciones propias. Tal inversión sólo podrá practicarse en instrumentos de renta fija, clasificados en categoría "A", según dos clasificadoras privadas o instrumentos emitidos o garantizados por el Estado hasta su total extinción y cuyo vencimiento no puede exceder el programa y oportunidades de desembolso de tales recursos.

La categoría "A", conforme a lo establecido por el artículo 88 de la Ley núm. 18.045, corresponde a aquellos instrumentos que cuentan con una buena capacidad de pago del capital $e$ intereses en los términos y plazos pactados, pero esta es susceptible de deteriorarse levemente ante posibles cambios en el emisor, en la industria a que pertenece o en la economía.
Los valores en que el administrador extraordinario invierta los recursos que tenga a su cuidado deben ser mantenidos en depósito en las entidades especiales a que se refiere la Ley núm. 18.876, de 1989 sobre constitución y operación de entidades privadas de depósito y custodia de valores.

Podrán actuar como administradores extraordinarios las mismas entidades que pueden actuar como representante de los tenedores de bonos, esto es, los bancos, instituciones financieras y demás personas que especialmente autorice la Superintendencia de Valores y Seguros para tal efecto.

El administrador, los encargados de custodia y los peritos calificados, tal como ocurre con el representante de los tenedores de bonos, también son designados por el emisor y, por esta razón, también resultan ser esencialmente removibles, requiriéndose para ello, el voto conforme de la mayoría absoluta de los votos correspondientes a los tenedores de bonos en circulación de la emisión respectiva asistentes a la junta, excluidos aquellos que fueran personas relacionadas con el emisor.

Si no hubiere acuerdo respecto a la persona del administrador, encargado de custodia o perito, corresponderá que este sea designado por él o los árbitro(s) encargados de resolver las controversias que se susciten entre las partes, debiendo recaer, necesariamente, tal designación en un banco, cuya solvencia haya sido acreditada con la calificación de los títulos que emite en las categorías A o B durante los últimos doce meses.

Si bien se contempla esta regla que exige el nombramiento de un administrador extraordinario cuando se exceda de determinado porcentaje del capital social de la empresa antes de la emisión, cabe tener presente que en el régimen chileno no hay una restricción que impida emitir bonos por sobre determinada suma. Criterio que no se repite en otros países de la región, donde sí se establecen límites 
numéricos respecto a la suma que puede comprender la emisión respectiva. Así, por ejemplo, ocurre con el artículo 550 del Código de Comercio de Guatemala que señala:

El valor total de la emisión no excederá del monto del capital contable de la sociedad creadora, con deducción de las utilidades repartibles que aparezcan en el balance que se haya practicado previamente al acto de creación, a menos de que las obligaciones se hayan creado para destinar su importe a la adquisición de bienes por la sociedad. En este caso, la suma excedente del capital autorizado podrá ser hasta las tres cuartas partes del valor de los bienes.

En el Paraguay, por su parte, si bien el artículo 70 de la Ley 1284 de 1998 establece un límite del 75\% para la emisión de bonos, en atención al patrimonio neto de la sociedad emisora, cuando se trate de entidades que no cuentan con información histórica o que con la que disponen es insuficiente, no se contemplan mecanismos de protección adicionales a los tenedores de bonos (del calibre del administrador extraordinario).

\subsection{Encargado de custodia}

Como hemos mencionado es la sociedad anónima especial que recibe y custodia los recursos manejados por el administrador extraordinario, en los supuestos que proceda su nombramiento, conforme a lo ordenado por el artículo 114 de la Ley núm. 18.045, que a su vez, se remite para estos efectos, a las normas contenidas en la citada Ley núm. 18.876.

Estas sociedades, de acuerdo a lo establecido por el por el artículo 116 de la Ley núm. 18.045 quedan también sujetas a la vigilancia de la Superintendencia de Valores y Seguros.

\subsection{Peritos}

Son aquellos a quienes el administrador extraordinario debe consultar cuando resulte pro- cedente, para efecto de ir verificando el cumplimiento de determinados requisitos técnicos establecidos en la escritura de emisión de los bonos, lo cual permitirá que este se encuentre habilitado para ir liberando los fondos respectivos.

El pronunciamiento de estos peritos, que son independientes pero remunerados por el emisor, es obligatorio para el administrador extraordinario.

\section{PROCEDIMIENTO DE EMISIÓN DE BONOS EN EL MERCADO DE VALORES CHILENO}

El legislador para emitir los bonos ha establecido un procedimiento sujeto a una serie de formalidades, que busca dar publicidad y con ello informar a los futuros tenedores de las características y condiciones del título de deuda que se les está ofreciendo.

\subsection{Celebración del contrato de emisión mediante escritura pública}

Se redacta el contrato de emisión de bonos a través de una escritura pública, suscrita entre el emisor y el representante de los (futuros) tenedores de bonos, en la cual se consignan las características y modalidades de la emisión, conforme a lo establecido en el artículo 104 letra c) de la Ley núm.18.045. Tal escritura, más el prospecto de la emisión que contiene las características de la misma y otros antecedentes adicionales, deben ser acompañados a la Superintendencia mediante carta firmada por el Gerente General de la sociedad emisora, junto con una copia del Acta en que la sociedad autorizó la emisión respectiva, con indicación de sus características principales.

En aquella escritura debe consignarse la información jurídica y económica del emisor, del representante de los tenedores de bonos y, en su caso, del administrador extraordinario y del encargado de custodia con sus respectivas remuneraciones. 
Además, debe describirse la emisión incluyendo el monto de esta, las series, cupones y características de los títulos, plazos de colocación, intereses y reajustes, formas y oportunidades de amortización, sorteos y recates, fechas y modalidades de pago y las garantías respectivas.

Otro elemento que debe consignarse en tal escritura es la naturaleza del arbitraje a que deban someterse las controversias que se produzcan con ocasión de la emisión, de su vigencia o extinción, en mérito a lo establecido en el artículo 105 de la Ley núm. 18.045.

En la sección IV de la Norma General Número 30 de la Superintendencia de Valores y Seguros se detalla de manera más pormenorizada cuáles son las menciones que tal escritura debe contener.

Cabe tener presente que el artículo 118 de la Ley núm. 18.045 consagra una regla natural, relativa a las características consignadas en el proceso de emisión de bonos respectivos, al decirnos que:

La suscripción o adquisición de bonos implica para el suscriptor o adquirente, la aceptación y ratificación de todas las estipulaciones, normas y condiciones establecidas en la escritura de emisión y en los acuerdos que sean legalmente adoptados en las juntas de tenedores de bonos.

No desconoce los derechos y obligaciones que en él se consagran o que se vayan adoptando en las juntas citadas para tal efecto, bajo el marco de los quórum respectivos.

En el Uruguay encontramos una norma análoga en lo establecido en el artículo 68 de la Ley de Mercado de Valores de ese país, rotulada como efecto jurídico de la adquisición de obligaciones negociables, al prescribir que la adquisición de obligaciones negociables importará la aceptación y la ratificación de todas las estipulaciones, las normas y las condicio- nes de la emisión y del contrato fiduciario, si lo hubiere.

En el Perú, las menciones que debe contener la emisión de bonos se contemplan en el artículo 88 de la Ley del Mercado de Valores de ese país, donde se dice que al menos debe contener:

a) Las características de la emisión concernientes a:

i. Importe total, series y cupones;

ii. Valor nominal, plazos, período de gracia, tasa de interés, primas si las hubiere y tasa de reajuste del valor nominal, de acuerdo a lo establecido en el artículo 1235 del Código Civil, si fuere el caso;

iii. Sorteos, rescates y garantías, si las hubiere; $y$,

iv. Descripción de los aspectos relevantes del programa de emisión a que pertenecen los valores, de ser el caso.

b) Restricciones al actuar del emisor y responsabilidades que le corresponde asumir en salvaguarda de los intereses de los obligacionistas, tales como:

i. El suministro continúo de información relativa a su marcha económico-financiera y a cambios en su administración;

ii. La conservación y la sustitución de los activos afectados en garantía exclusiva de los obligacionistas;

iii. El derecho de los obligacionistas a disponer inspecciones y auditorías;

iv. El procedimiento para la elección del representante de los obligacionistas; y

v. Los deberes y responsabilidades que recaen sobre el representante de los obligacionistas;

c) Las disposiciones sobre el arbitraje de los conflictos entre la sociedad, los obligacionistas y el representante de los obligacionistas que provengan o se relacionen con las obligaciones y derechos que se derivan de los términos de la emisión, de la Ley de Sociedades o de la presente ley, de acuerdo a lo previsto en el Título XII; y, 
d) Toda otra información que establezca CONASEV (actual Superintendencia del Mercado de Valores) mediante disposiciones de carácter general.

\subsection{Inscripción en el Registro de Valores}

Se solicita la inscripción de los bonos en el Registro de Valores, que lleva la Superintendencia de Valores y Seguros, acompañando para tal efecto la información jurídica y económica del emisor, administrador extraordinario, encargado de custodia y representante de los tenedores, y dos informes de clasificadoras de riesgo, que evaluarán la posibilidad de que los acreedores puedan ser reembolsados del crédito conferido, al clasificar los instrumentos conforme a las categorías establecidas en el Art. 88 de la Ley núm. 18.045, esto es, AAA, AA, A, BBB, BB, B, C o D.

El que se acompañen tales clasificaciones de riesgo resulta fundamental, pues si bien quien invierte en el mercado de valores no tiene una ganancia asegurada, y siempre está la posibilidad de que eventualmente no recupere su inversión o recupere una suma menor a la invertida, motivo por el cual resulta necesario que esté informado de los riesgos, según el instrumento respectivo y la consiguiente solvencia y capacidad de pago del emisor (Zunzunegui, 2006, p. 194).

Una vez verificada la inscripción, el emisor debe publicar, al menos en dos diarios de circulación nacional, un aviso dirigido al público inversionista informando sobre las principales características de la emisión y de la sociedad emisora.

En el Uruguay, el Registro de Valores está entregado, conforme a lo establecido en el artículo $3^{\circ}$ de la Ley de Mercado de Valores de ese país, a la Superintendencia de Servicios Financieros, la cual se encuentra habilitada para prever requisitos diferenciados, en atención al tipo de valor, la oferta, el inversor al cual va dirigida, asegurando la debida información respecto de la característica de la emisión y del régimen al que se encuentra sujeto.

Ahora bien, no obstante se contemplen los roles indicados a la Superintendencia de Servicios Financieros, la Ley aludida entrega una serie de facultades para velar por la transparencia, competitividad y funcionamiento ordenado del mercado de valores, la adecuada información de los accionistas y la reducción del riesgo sistémico al Banco Central de ese país, entidad de la cual depende la citada Superintendencia.

\section{MECANISMOS ESPECIALES QUE BUSCAN VELAR POR EL INTERÉS DE LOS TENEDORES DE BONOS}

El legislador ha establecido un régimen especial de protección de la acreencia que detentan los tenedores de bonos fijando, para ello, normas particulares excepcionales, si se les mira con las cláusulas del Derecho Civil, como ocurre con las cláusulas de no enajenar, y con las normas generales del Derecho societario en materia de posibilidad de renunciar al arbitraje, por solo mencionar algunos casos, lo que denota la preocupación por el correcto funcionamiento del mercado de valores, atendidas las particularidades de éste en el país, y habida cuenta de que en este caso estamos ante instrumentos de renta fija que, en principio, suponen menos riesgo para los inversores.

\subsection{Límites en relación de endeudamiento del emisor}

Pueden pactarse límites en la relación de endeudamiento del emisor, indicarse también la finalidad del proyecto para el cual se requiere el financiamiento y el uso que se dará a los recursos que con la emisión se obtengan, y eventual política de inversión que deba seguir el administrador extraordinario, dados los revisados términos del artículo 112 de la Ley núm. 18.045. 
Aquellos administradores extraordinarios, como ya se ha señalado, deberán seguir las pautas y autorizaciones que les den los peritos calificados, establecidos para tal efecto, en caso de ser necesario, según las condiciones específicas del proyecto.

\subsection{Cláusula de Aceleración}

Otra alternativa en defensa de los tenedores de bonos es que se establezca una cláusula de aceleración ante el incumplimiento por parte del emisor de las obligaciones asumidas. En tal caso, para que sea procedente aquella aceleración, será necesario contar con el voto conforme de la mayoría de los tenedores, sin que quepa el cobro anticipado por uno o más tenedores en particular. Aquella mayoría que también es necesaria para la resolución del contrato de emisión, la solicitud de quiebra o la solicitud de un convenio preventivo u extrajudicial (Puga, 2011, p. 328).

\subsection{Otras cauciones}

Del mismo modo, pueden pactarse distintas garantías que caucionen la obligación asumida por el emisor, conforme a lo señalado por el artículo 119 de la Ley núm. 18.045.

Si se constituyen garantías reales, como prendas e hipotecas, figurará como acreedor prendario u hipotecario, para efectos de la necesaria individualización de este, el representante de los futuros tenedores de bonos. Disposición que resulta casi idéntica a la norma establecida en el artículo 75 de la Ley Uruguaya de Mercado de Valores, pues es de toda lógica, que el legislador en ambos países haya buscado facilitar y hacer más expedito el establecimiento de estos mecanismos que buscan asegurar el pago a los acreedores que invierten en este tipo de instrumentos, sin que sea necesario entrabar los procesos de caución, con formalismos o solemnidades como la individualización específica de los tenedores (obligacionistas) beneficiados con ellas.
Del mismo modo, en el Perú, el inciso segundo del artículo 90 de su Ley del Mercado de Valores dispone que para la inscripción o registro de las garantías no es necesario individualizar a los "obligacionistas" y basta que se consigne el nombre del representante de éstos.

A su vez, las distintas notificaciones que deban realizarse al acreedor prendario o hipotecario se entenderán válidamente practicadas si se efectúa al representante de los tenedores de bonos, tanto en Chile como en los otros países expuestos en esta materia.

Una garantía particular del proceso de emisión de bonos hace relación con un fondo de garantía especial para los tenedores, establecido por el artículo 112 inciso octavo de la Ley núm.18.045, que nos dice que en la escritura de emisión se puede formar este fondo, que será administrado e invertido por el administrador extraordinario, en los bienes y forma establecida en el artículo 113, materia a la que ya nos referimos al enunciar a este sujeto participante del proceso de emisión de bonos.

Aquella masa que tiene a cargo el administrador extraordinario, sus inversiones, reajustes, rentabilidades e incrementos de cualquier naturaleza, se entenderán legalmente constituidos en prenda, en garantía del cumplimiento a favor de los tenedores de bonos.

El inciso tercero del artículo 114 de la Ley núm. 18.045 es enfático al señalar que sobre aquella masa no se reconocerá otra garantía, y cualquier otra caución que se establezca sobre esta o pretenda constituirse sobre aquella quedará sin efecto "de pleno Derecho", con lo cual el legislador es enfático y utiliza uno de aquellos términos que han dado lugar a profundas discusiones doctrinarias en materia civil relativas a la recepción o no dentro de nuestro Derecho de la inexistencia jurídica como sanción de ineficacia jurídica.

Añade el legislador que los bienes de aquella masa solo podrán ser embargados en juicio por los acreedores garantizados (los tenedores 
de bonos), en cuanto ejerzan acciones protegidas por esa garantía, excluyendo a cualquier otro acreedor de la posibilidad de que, en ejercicio del derecho de prenda general que detente, pueda perseguir su crédito sobre aquel conjunto de bienes.

Se señala además que tal prenda legal prevalece incluso sobre los créditos de primera clase y también sobre aquellos establecidos en leyes especiales, al decirnos que:

(...) los tenedores de bonos, podrán pagarse del monto íntegro de sus créditos, reajustes, intereses y costos de cobranza, con preferencia a cualquiera otra obligación, incluidos los derivados de los créditos de primera clase a que se refiere el artículo 2472 del Código Civil y de cualquiera otra al que leyes especiales le otorguen preferencia especial.

La única excepción a este régimen tan preferente para los tenedores de bonos son las costas arbitrales y la remuneración del representante de los tenedores de bonos, cuyo crédito prevalece frente al de los tenedores, estableciendo un privilegio especial en defensa de los tenedores de bonos que, a nuestro juicio en cierta medida, resulta ser algo excesivo, pues no nos parece adecuado que prime incluso frente a otros créditos como las remuneraciones, cotizaciones adeudadas y asignaciones familiares de los trabajadores de la sociedad emisora.

No es menor, lo que se indica en el inciso séptimo de este mismo artículo 114 , que nos dice que en caso de quiebra del emisor, los bienes de este patrimonio especial se excluyen de la masa de bienes del fallido, y los tenedores serán pagados sin la necesidad de aguardar las resultas de la quiebra y sin que sea necesario formular ninguna de las reservas contenidas en la Ley núm. 18.175, Ley de Quiebras, en especial las de su artículo 149.

Luego, para dar seguridad a esta disposición, el inciso final del artículo 114 de la Ley núm. 18.045 prescribe que la preferencia estable- cida en esta disposición y sus modalidades especiales, solo podrán ser derogadas expresamente por otra norma legal, lo que no hace sino reafirmar más aún la preferencia especial consagrada para estos acreedores.

\subsection{Obligaciones, limitaciones y prohibiciones adicionales a las establecidas por el legislador}

El emisor además para hacer más atractivo su instrumento de deuda puede adoptar otra serie de medidas adicionales, que el señor Puga ha denominado "limitaciones a la operación de la compañía durante el plazo de emisión” (2011, p. 324).

Aquellas limitaciones que supongan delegar facultades que detente la Junta General de accionistas de la sociedad deberán estar expresamente detalladas y especificadas y, para que sean válidas, deberán ser adoptadas con el voto conforme a la mayoría absoluta de las acciones emitidas con derecho a voto o con el quórum mayor que para este efecto establezcan los estatutos respectivos o la ley, en su caso (Ortega, 1997, p. 173), y estos se tendrán por no acordados o no escritos si no se anotan al margen de la inscripción de la constitución de la emisora, una referencia indicativa a la escritura que da constancia de su existencia dentro de los 60 días siguientes a la fecha de su otorgamiento.

En esta materia, el legislador da lugar a lo que se han denominado cláusulas pari passu, en virtud de las cuales el deudor (emisor) se obliga a no constituir prendas, hipotecas $u$ otro tipo de créditos privilegiados, y en el evento de que no dé cumplimiento a tal compromiso los acreedores (tenedores de bonos) se encuentren habilitados para acelerar el reembolso de la deuda (events of default).

Una figura que cuenta con normativa especial es la contenida en el artículo 111 de la Ley núm. 18.045, que da lugar a que pueda pactarse en la escritura de emisión "resguardos para los inversionistas", en virtud de los cuales 
sin expresa autorización del representante de los tenedores de bonos, la sociedad emisora no se encuentra habilitada para celebrar acuerdos o realizar determinadas negociaciones.

Estos son los denominados Covenants, esto es, cláusulas contractuales convenidas en los contratos de préstamos u otros de esta naturaleza, mediante las cuales se imponen a la sociedad emisora (prestataria) obligaciones de hacer o no hacer con el objetivo de limitar su libertad de endeudamiento (evitar riesgos), buscando que se asegure y permanezca la capacidad de pago y reembolso del prestatario.

Tales covenants pueden clasificarse en prohibitivos/imperativos, según si impiden u obliguen una determinada conducta o acto; absolutos/condicionados, según si se aplican en todo caso o si operan una vez verificados determinados supuestos; de ejecución instantánea/ de ejecución diferida, según si operan de una sola vez o suponen una obligación que perdura durante el tiempo que esté vigente la emisión, etc. (Araya \& Maqueira, 2002, pp. 10-11).

Respecto a la efectiva utilización de este tipo de cláusulas en los procesos de emisión que tienen lugar en Chile, una interesante muestra al año 2000 de estos les clasificó y agrupó constatando que, en virtud de ellos, en un $80 \%$ de los casos se restringe de alguna forma la política de inversión o de producción de la sociedad emisora, que en un $80 \%$ de las emisiones se exigen el desarrollo de actividades de monitoreo, que en un $83 \%$ de las emisiones se establecen restricciones a las políticas de endeudamiento, que en un 91\% de estas se convienen cláusulas que permiten alterar el patrón de pago, y que un $3 \%$ de las emisiones presentan cláusulas que limitan la política de reparto de dividendos (Araya \& Maqueira, 2002, p. 21).

Especial relevancia cobra el hecho de que se ha establecido en el artículo 111 de la Ley núm. 18.045, que el incumplimiento a tales acuerdos conduce a la nulidad absoluta de tales actuaciones celebradas en contravención de aquellas prohibiciones de celebrar determinados contratos, haciendo, además, a los administradores de aquellas sociedades emisoras que infrinjan tales pactos, solidariamente responsables de los daños y perjuicios que pudieren causar en los tenedores de bonos. He aquí una sanción especial contemplada por el legislador mercantil, que es más fuerte a la que generalmente se ha sostenido procede, en sede civil, ante la infracción de una obligación de no hacer (no enajenar u otra similar), como veremos más adelante, con lo cual podemos apreciar cómo se quiso dar una protección especial a los inversionistas en este tipo de instrumentos de renta fija.

Como se puede ver, el alcance de esta prohibición de enajenar puede ser mucho más amplia que aquella figura propia del Derecho Civil, la cual consiste en circunscribir determinados inmuebles a una prohibición de enajenar por parte del titular de estos que, para tal efecto, específicamente ha habilitado en el Conservador de Bienes Raíces un Libro especial de Interdicciones y Prohibiciones de Enajenar en el cual, según lo establecido por el artículo 53 N.. 3 del Reglamento del citado Conservador, puede inscribirse todo impedimento o prohibición referente a inmuebles, sea convencional, legal o judicial, que embarace, límite de cualquier modo el libre ejercicio del derecho de enajenar, puesto que la limitación a la que estamos aludiendo podría incluso comprender voluntariamente y de modo convencional o unilateral los bienes muebles, restringiendo, con carácter general, las facultades de disposición respecto a los distintos bienes que formen parte del patrimonio de la sociedad emisora.

Es preciso entonces, conocer el estado de cosas en materia civil, adelantando desde ya que este no ha sido un asunto pacífico, ya que a lo largo de los años se han formulado diferentes opiniones por parte de los autores nacionales, respecto a la posibilidad de conferir o no validez a este tipo de cláusulas de no disponer (de manera general) convencionalmente acordadas, y luego, en caso afirmativo, esto es que se le entienda como válidas, corresponde esta- 
blecer qué efecto jurídico traerá aparejado el incumplimiento de aquel pacto de no hacer.

Sobre este punto, los profesores Peñailillo Arévalo (1980, p. 3), Pinochet Olave (2008, p. 19) y Alessandri Besa (2008, pp. 185-188) le reconocen validez a las cláusulas de no enajenar, siempre y cuando tal cláusula se haya pactado por un tiempo determinado y con causa legítima.

La necesidad de que tal pacto obedezca a una causa legítima o lícita es corolario de la causa lícita como requisito de validez de los actos jurídicos, en los términos del artículo 1467 del Código Civil.

Respecto a este segundo requisito mencionado, el profesor Pinochet Olave (2008, pp. 20-21) pone especial énfasis en la necesidad de que aquella cláusula haya sido acordada de manera voluntaria, como una manifestación del ejercicio de la autonomía de la voluntad, lo que muchas veces queda en entredicho en los contratos de adhesión, que es precisamente en los cuales muchas veces figura este tipo de acuerdos, por lo cual, señala que se debe hacer un análisis del caso concreto para brindar o no validez a tal tipo de estipulaciones.

Ahora bien, que se le confieran validez $y$, por ende, no las consideren anulables, no supone que tal cláusula resulte ser oponible a terceros (Alessandri \& Somarriva, 1957, p. 165), ya que los citados autores entienden que tal pacto vincularía solamente a las partes que lo acordaron, por lo que los efectos del incumplimiento de este deberá resolverse conforme a las normas que regulan la infracción a las obligaciones de no hacer.

Tales ideas operan sobre la base de la protección de la buena fe del tercero contratante, que en principio no estaría en condiciones de conocer este tipo de acuerdos, lo que en cierta medida se ve mitigado, habida cuenta de la necesidad de inscribir dentro de 60 días este tipo de pactos especiales, en los términos del inciso quinto del artículo 111 de la Ley núm. 18.045.
Continuando con las otras tendencias doctrinarias es el turno de mencionar que otros autores, como don José Clemente Fabres (Kiverstein, 1957, pp. 28-29) y el profesor Rozas Vial (2006, p. 82) en cambio, les reconocen validez general a este tipo de cláusulas limitativas, sin sujetarle a requisito alguno, a menos que se trate de aquellos casos en que tal estipulación se encuentre prohibida por el legislador. Concluyendo también que la sanción a la infracción de estos acuerdos será la una indemnización de perjuicios, por haber violentado una obligación de no hacer ya que tal acuerdo no puede, en principio hacerse oponible a terceros de buena fe que contrataron con la entidad obligada.

Por el contrario, un tercer sector doctrinario, encabezado por don Luis Claro Solar (1979, p. 339), en el que encontramos también a otros autores como el profesor Vitorio Pescio Vargas (1958, pp. 311-314) ha señalado que es nulo todo pacto en que un propietario renuncie a la posibilidad de disponer de sus bienes de manera absoluta, puesto que tal acuerdo adolecería de objeto ilícito por contravenir normas de orden público, como las contenidas en los artículos 582 y 1810 del Código Civil y también las ideas centrales de este cuerpo normativo, inspiradas en la libre circulación de los bienes, contenidas en su mensaje. Agregando que sólo la ley puede establecer limitaciones a la enajenación de los bienes por parte del propietario, quedando vedada tal posibilidad para acuerdos convencionales.

De modo tal que para este último sector de autores, mal puede tener alguna sanción la infracción a un acuerdo que adolece de un vicio de nulidad absoluta por contravenir el orden público.

Interesante resulta entonces apreciar la manera cómo el legislador en el caso de la emisión de bonos da una protección especial a estos inversionistas, pues al mismo tiempo que por mandato legal brinda validez a este tipo de cláusulas de no enajenar, sanciona la infracción de aquel pacto con la nulidad absoluta del 
acuerdo que violente ese acuerdo de no disponer (o no hacer) acordado, sanción muy distinta a la que se ha concluido procede en sede civil general, en que, en términos amplios, se ha dicho que lo que corresponde es indemnizar a la parte vulnerada en sus expectativas por el incumplimiento de la obligación de no hacer estipulada, pero sin afectar el contrato celebrado en contravención de ésta.

Para cerrar esta temática de las limitaciones a la disposición por parte del emisor, creemos oportuno señalar que lo que no podrá hacerse en virtud de tales delegaciones o restricciones a que se somete el emisor es restringir el reparto de dividendos obligatorios (que en Chile según la Ley de Sociedades Anónimas no pueden ser inferiores al 30\% de las utilidades de la sociedad, a menos que la unanimidad de los accionistas acuerde lo contrario), pues aun cuando sea importante velar por proteger a los tenedores de bonos, no se puede por tal causa vulnerar las legítimas expectativas de los accionistas minoritarios, sujetos especialmente protegidos en nuestra legislación mercantil.

Por lo demás, esta disposición resulta necesaria coordinarla con lo establecido en el inciso final del artículo 2070 de nuestro Código Civil, en virtud del cual los accionistas de sociedades anónimas en ningún caso estarán obligados a devolver a la caja social las cantidades que hubieren percibido a título de beneficio, motivo por el cual, dentro de nuestro ordenamiento jurídico sería jurídicamente viable el que una sociedad emisora reparta utilidades, no obstante mantenga insoluta el pago de una acreencia, con los tenedores de bonos, a modo de ejemplo, encontrándose para ello, amparado en las citadas normas legales (Lyon, 2003, pp. 203- 204).

De ahí que resulte crucial el papel que juegue el representante de los tenedores de bonos, en sus funciones de monitoreo de la sociedad emisora, buscando que los acreedores de este instrumento de renta fija, no se vea enfrentado a la situación descrita, de no poder perseguir las utilidades ya repartidas a título de dividendo.
Muy distinta es la situación que se da en el Uruguay donde, precisamente, el artículo 78 de la Ley Uruguaya de Mercado de Valores impide el reparto de dividendos entre los accionistas en el evento que la sociedad emisora esté en mora del pago a los obligacionistas.

\subsection{Mérito ejecutivo}

Conforme a lo establecido en el artículo 120 de la Ley núm. 18.045, los bonos vencidos por expiración de plazo gozan de mérito ejecutivo, constituyendo un caso más dentro del ordenamiento jurídico chileno de títulos especiales, que con atención a las particularidades propias, el legislador les ha brindado este carácter que facilita su cobro, como también ha ocurrido en otros caso, como por ejemplo con la factura, que a través de la Ley núm. 19.983 de 2004, que le otorgó mérito ejecutivo a la copia de la factura, por solo mencionar algunos ejemplos.

Debemos mencionar, que disposiciones análogas también las encontramos en el Derecho comparado regional, y así el artículo 77 de la Ley Uruguaya de Mercado de Valores le confiere tal carácter a este tipo de instrumentos de renta fija, y también la Ley núm. 27.287, de 2000, del Perú, que le dio tal cualidad a los títulos valores, en su Art. 18.

\subsection{Forma de resolver las controversias que se susciten}

Siguiendo la orientación que se da para las controversias societarias, las diferencias que se produzcan con ocasión de la emisión de los bonos, su vigencia o extinción, se someterán a arbitraje, y en el evento de que en la escritura de emisión no se señale la naturaleza de éste, aquellos árbitros conocerán con el carácter de arbitradores, según lo prescrito por la letra h) del artículo 104 de la Ley núm.18.045.

El o los árbitros serán designados de común acuerdo por las partes en conflicto, sin que puedan estar predeterminados en la escritura elaborada por el emisor. En el evento que no 
se alcance acuerdo sobre los nombres de tales árbitros, la designación deberá efectuarla la justicia ordinaria.

Ahora bien, sobre esta materia conviene destacar que también se brinda un régimen especial a favor de los tenedores de bonos, ya que si bien algunos (Puga, 2011, p. 325) han sostenido que aquellos asuntos serían objeto de arbitraje forzoso, no es menos cierto que a estos acreedores se les da siempre la posibilidad de desechar aquella alternativa, brindándoseles la posibilidad de iniciar las acciones respectivas ante la justicia ordinaria, opción que no se brinda a la sociedad emisora, sino que solo a los tenedores.

Lo anterior se ha interpretado (Vásquez, 2009, p. 545) en el sentido de que aun cuando existiere un convenio arbitral válido entre las partes, el demandante (tenedor de bonos) puede someter el asunto al conocimiento de los tribunales ordinarios de justicia.

A todo lo anterior, se suma el hecho de que las costas procesales que demande el arbitraje deberán ser solventadas por quien lo haya promovido, a menos que se trate de conflictos en que sea parte el emisor, en cuyo caso será este quien deberá sufragar con los honorarios del árbitro y las costas que se vayan generando, quedando -con todo- la posibilidad de que repetir en contra de la parte que, en definitiva, sea condenada al pago de las costas.

\section{CONCLUSIONES}

A lo largo de este informe hemos intentado exponer un panorama general del proceso de emisión de un instrumento de renta fija, instrumento de deuda que cuenta con una regulación especial en el país, y que constituye un medio de financiamiento para las empresas chilenas que, día a día, en atención a sus objetivos de expansión, requieren de los recursos necesarios para instalarse más allá de nuestras fronteras.
Si bien una visión parcial de este instrumento nos permite analizarlo como una vía para obtener recursos para de las empresas, hemos tenido ocasión de describir los diferentes mecanismos en defensa de los tenedores de bonos que el legislador ha establecido, configurando un régimen excepcional que confiere a tales acreedores de una serie de prerrogativas que buscan garantizar su efectivo derecho de prenda general, en una posición bastante más aventajada a la que queda un acreedor del derecho común.

A nuestro juicio, con este régimen se busca velar por el necesario resguardo de la fe pública, tan importante en el correcto funcionamiento del mercado de valores, imponiendo a las empresas emisoras de tales instrumentos de deuda una serie de requisitos, estableciendo reglas tendientes a asegurar el cumplimiento de sus obligaciones una vez que hayan decidido obtener recursos del público en general por esta vía, lo que no deja de ser positivo para el correcto desempeño del mercado de capitales, cuyo éxito no solo tiene consecuencias en los inversores de carácter particular, sino que también en los todos los trabajadores del país, dado el sistema de seguridad social, en particular de régimen de pensiones, instaurado a inicios de los años ochenta, pero que a su vez, en determinados puntos parecen resultar excesivos, dados los demás resguardos especiales para la correcta inversión de las cotizaciones previsionales.

En definitiva, siempre será necesario alcanzar un justo punto medio que concilie los intereses de emisores e inversionistas, deudores y acreedores, que dentro de un marco de certeza, con un régimen claro y bien consolidado puedan adoptar sus decisiones debidamente informados, para así, obtener el mejor provecho que permita beneficiar a los distintos sujetos ligados al mercado de capitales como un todo, cuyas desaciertos, demás está decirlo, pueden acarrear nocivas consecuencias sociales, mucho más allá de los particulares agentes que intervinieron en las operaciones respectivas. 


\section{REFERENCIAS}

Alessandri, A. (2008). La nulidad y la rescisión en el Derecho Civil chileno, t. I, Santiago de Chile: Editorial Jurídica de Chile.

Alessandri, A. \& Somarriva, M. (1957). Curso de Derecho Civil, t. II De los Bienes, Santiago de Chile: Editorial Nascimiento.

Araya, A.; Isla, G. \& Maqueira, C. (2002). Cláusulas restrictivas (covenants) en los contratos de bonos: evidencia empírica en Chile, Estudios de Administración, 9, 1.

Boneo, E. \& Barreira, E. (1994). Contratos Bancarios Modernos. Buenos Aires: Abeledo Perrot.

Camargo, V. (2007). Derecho Comercial Boliviano. La Paz: Grupo Impresor.

Claro, L. (1979). Explicaciones de Derecho Civil y Comparado. De los Bienes, Santiago de Chile: Editorial Jurídica de Chile.

García-Pita, J. (2009). Las entidades de crédito y sus operaciones. Vol. 5, Operaciones Bancarias Neutras. Madrid: Marcial Pons.

Kiverstein, A. (1957). Síntesis de Derecho Civil, t. II, de los objetos del Derecho. Bienes. Santiago de Chile: Edugal.

López, C. (2001). Financiación de proyectos (project financing). En Zunzunegui, F. (Coord). Lecciones de Derecho Bancario y Bursátil. Madrid: Colex.

Lyon, A. (2003). Personas Jurídicas. Santiago de Chile: Ediciones Universidad Católica de Chile.

Malumián, N. \& Barredo, F. (2007). Oferta Pública de Valores Negociables. Buenos Aires: LexisNexis.
Novoa, R. \& Novoa, G. (1997). Derecho del Mercado de Capitales. Santiago de Chile: Editorial Jurídica de Chile.

Ortega, A. (1997). Mercado de Valores. Teoría General Descriptiva y Legislación Chilena. Santiago de Chile: Ediciones Jurídicas La Ley.

Peñailillo, D. (1980). Prohibición de enajenar voluntaria y negativa del Conservador. Gaceta Jurídica, 32.

Pescio, V. (1958). Manual de Derecho Civil (De las personas, de los bienes y de la propiedad), t. III, Santiago de Chile: Editorial Jurídica de Chile.

Pinochet, R. (2008). Sobre la validez de las cláusulas de no enajenar: Un enfoque actual. Gaceta Jurídica, 337.

Puga, J. (2011). La sociedad anónima y otras sociedades por acciones en el Derecho chileno y comparado. Santiago de Chile: Editorial Jurídica de Chile.

Rodríguez, S. (2004). Contratos Bancarios. Su significación en América Latina. Bogotá: Legis.

Rozas, F. (2006). Los bienes. Santiago de Chile: Editorial Lexis Nexis.

Saieh, C. (2010). Derecho para el emprendimiento y los negocios. Santiago de Chile: Ediciones Universidad Católica de Chile.

Tapia, A. (1994) La captación de fondos del público en el Derecho español vigente. En Jornadas sobre productos financieros actuales. Madrid: Servicio de publicaciones de la Facultad de Derecho de la Universidad Complutense.

Torres, O. (2010). Derecho de Sociedades. Santiago de Chile: Abeledo Perrot Legal Publishing. 
Uría, R. (1989). Derecho Mercantil. Madrid: Marcial Pons.

Vásquez, M. (2009). Arbitraje en Chile, Análisis crítico de su normativa y jurisprudencia. Santiago de Chile: Legal Publishing.

Zunzunegui, F. (2006). Una aproximación a la protección del inversor en el mercado de valo- res. En Rodríguez, S., Rincón, E. \& Calderón, J. (Eds.) Temas de Derecho Financiero Contemporáneo. Bogotá: Editorial Universidad del Rosario.

Historia de la Ley núm. 19.301, Biblioteca del Congreso Nacional de Chile, versión impresa. 